Peer Reviewed Paper openaccess

\title{
Spatial analysis of Hyperion hyperspectral indices to map the vegetation state in the coastal oases of Tunisia
}

\author{
Rim Katlane, ${ }^{a *}$ Jean-Claude Berges ${ }^{\mathrm{b}}$ and Gérard Beltrando $\mathrm{b}^{\mathrm{b}, \mathrm{c}}$ \\ aGEOMAG (LR19ES07)/PRODIG (UMR 8586), University of Mannouba-Tunis, Campus universitaire B.P.95 2010 Mannouba, Tunisia \\ buniversité Diderot, Sorbonne Paris-Cité, (PRODIG), 75205 Paris Cedex 13, France \\ 'Gérard Beltrando died on 28 January 2016 \\ Contacts
}

Rim Katlane: katlanerim@yahoo.fr

Jean-Claude Berges: jean-claude.berges@univ-paris1.fr

https://orcid.org/0000-0003-4670-8146

An elevated human presence due to the involvement of the coastal oases of Tunisia in the global petrochemical industry and population pressure in the 1970s has resulted in major changes in the oases' agro-ecosystem environment. The consequences of this have been urbanisation and rural exodus, priority to the industrial sectors and services at the expense of agriculture, high mobility and rise of trade. The coastal oases of Gabes located in the South-East of Tunisia are considered in this study. This has been affected by sharp degradation, mainly of anthropogenic origins such as demographic growth, extension of the urban areas and creation of a highly contaminating chemical zone amplifying their environmental vulnerability. Satellite data is an essential tool in the study and mapping of these types of environment and for that, we started with the mapping of the vegetative land use using the vegetation indices derived from the hyperspectral scene of the Hyperion sensor (25 April 2010) and field data. This has allowed us to better characterise the most vulnerable areas and to identify the socio-environmental risks. The analysis of the radiometric indices leads to the definition of the spatial extension of vegetation cover in the oases. This study has permitted us to outline the oases' typologies in Gabes and to discuss their dynamics in the short term.

Keywords: Gabes, coastal oases, state of vegetation cover, Hyperion sensor, radiometric indices

\section{Introduction}

Environmental changes driven by human activities have disrupted the agro-ecosystem of the coastal oases of Tunisia over the last few decades. The present study is conducted in the coastal oases of Gabes, a unique maritime territory in the Mediterranean basin, ${ }^{1}$ located in the south-east of Tunisia. These oases are undergoing multicausal constraints that have modified their structural, hydraulic and socio-economic characteristics, amplifying their environmental vulnerability. Locally, these have made it difficult to distinguish between traditional
Correspondence

R. Katlane (katlanerim@yahoo.fr)

Received: 17 September 2020

Accepted: 30 September 2020

Publication: 16 October 2020

doi: 10.1255/jsi.2020.a11

ISSN: 2040-4565

\author{
Citation \\ R. Katlane, J.-C. Berges and G. Beltrando, "Spatial analysis of Hyperion \\ hyperspectral indices to map the vegetation state in the coastal oases of \\ Tunisia", J.Spectral Imaging 9, a11 (2020). \\ https://doi.org/10.1255/jsi.2020.a11 \\ (c) 2020 The Authors \\ This licence permits you to use, share, copy and redistribute the paper in \\ any medium or any format provided that a full citation to the original \\ paper in this journal is given, the use is not for commercial purposes and \\ the paper is not changed in any way.
}


and new oases. The traditional oases are structured in three vegetation layers and marked by the presence of palm trees, ${ }^{2}$ while the perimeters of the new oases are characterised by open irrigated areas. ${ }^{3}$ So, there is the paradoxical phenomenon of both agricultural decline and growth, respectively, in the old oases and the new irrigated perimeters. ${ }^{4}$ Recent studies have confirmed these observations. ${ }^{1,3}$ Therefore, under the influence of urban growth, many agricultural parcels of the old coastal oases territory have been reduced. On the hand, the new oases have been integrated into the complex process of globalisation: ${ }^{5}$ agricultural products that were limited to the local market in the past are now exported to Europe (pomegranates, olives).

In 1974, the development of the chemical and petrochemical industry in Gabes created thousands of salaried jobs to the detriment of shortages in traditional expertise and the farm labour force. These changes raise the question of competition in the use of water resources, which are crucial in this arid region. Besides the influences of climate change on water scarcity in Gabes, the water crisis has also been caused by a mismanagement of the hydro-agro ecosystems by local communities. , $^{6}$

Other research in geography, 1,3,6 and even in anthropology, ${ }^{2}$ was carried out on the changes in the structure of the oases of southern Tunisia, mainly the complexity of the oasis territory of Gabes with the analysis of the state of the plant cover and socio-environmental issues.

Moreover, new capabilities are offered by the Hyperion hyperspectral imaging and vegetation spectral indices for assessing the state of oases' vegetation cover. Hyperspectral remote sensors have been extensively tested for vegetation mapping (classification, species identification, disease detection). ${ }^{8}$ A study conducted in Australia on the mapping of invasive plants using Hyperion hyperspectral images ${ }^{9}$ showed that this technology provides a high level of accuracy, despite its spatial resolution of $30 \mathrm{~m}$. Hyperspectral imagery from a CASI (Compact Airborne Spectrographic Imager) has been used to detect vegetation diseases in Californian forest. ${ }^{10}$ A comparative analysis of hyperspectral sensors (Hyperion, IKONOS, ALI) and the Landsat-7 multispectral sensor (ETM+) has also been undertaken for the classification of the vegetation in the South Cameron rainforest ${ }^{11}$ showing that 23 Hyperion narrow bands (between $1300 \mathrm{~nm}$ and $1900 \mathrm{~nm}$ ) are adequate for modelling the evolution and nature of forest biomass.
In our research, fieldwork was performed to validate the hyperspectral data analysis. The evaluation method was conducted according to the spatial response from the hyperspectral indices derived from the Hyperion image. Field information was collected with the aim of deepening the interpretation of the spectral indices and refining the typology of the oases. The field protocol was split into two main steps: observations and questionnaires on the types and condition of the vegetation cover.

In this study, Hyperion hyperspectral images of the region of the city of Gabes (25 April 2010) were processed, analysed and validated for the spatial Hyperion hyperspectral indices used to map the vegetation cover in the coastal oases of Gabes.

\section{The study area}

The governorate of Gabes consists of a series of oases located in the Gulf of Gabes coastline. They cover an area of approximately 7000 ha $^{12}$ scattered over several sites: Oudref, Matouia, Bouchemma, Chott Essalem, Ghannouch, Chenini, Teboulbou, El M'dou and El Hamma. Most of them were created by water companies and consist of the steppe and irrigated areas as well as the oasis. ${ }^{3,12}$ They are characterised by three levels of vegetation (palm trees, fruit trees and herbaceous plants) irrigated by oueds fed by springs. Groundwater resources are vital in this arid and hot climate, which has an annual rainfall of about $190 \mathrm{~mm}$ and a very high annual evapotranspiration $(1400 \mathrm{~mm}) .{ }^{13}$ The central parts of Gabes' oases are called "traditional oases" or "mother oases" (e.g. Chenini, Teboulbou, Oudref; Figure 1) and "daughter oases", of which Ghannouch is the most typical example (Figure 1). In general, these "daughter oases" are periurban, since inhabited territories have grown toward them and are encroaching on their desert margins. The territories of these oases generally have two different layers of vegetation in which palm trees are scarcer ${ }^{12}$ and water resources are mostly phreatic. From the 1970 s, the Gabes oases have been affected by induatrialisation, characterised (at the level of agro-systems) by the creation of new irrigated areas in which management of land-use and water resources can be public or private. The water is often drawn from a deep aquifer. ${ }^{12}$ Owing to its geographical position between the sea and the desert, Gabes and its oases have a special history: they are located within the entry and exit transition zone of 


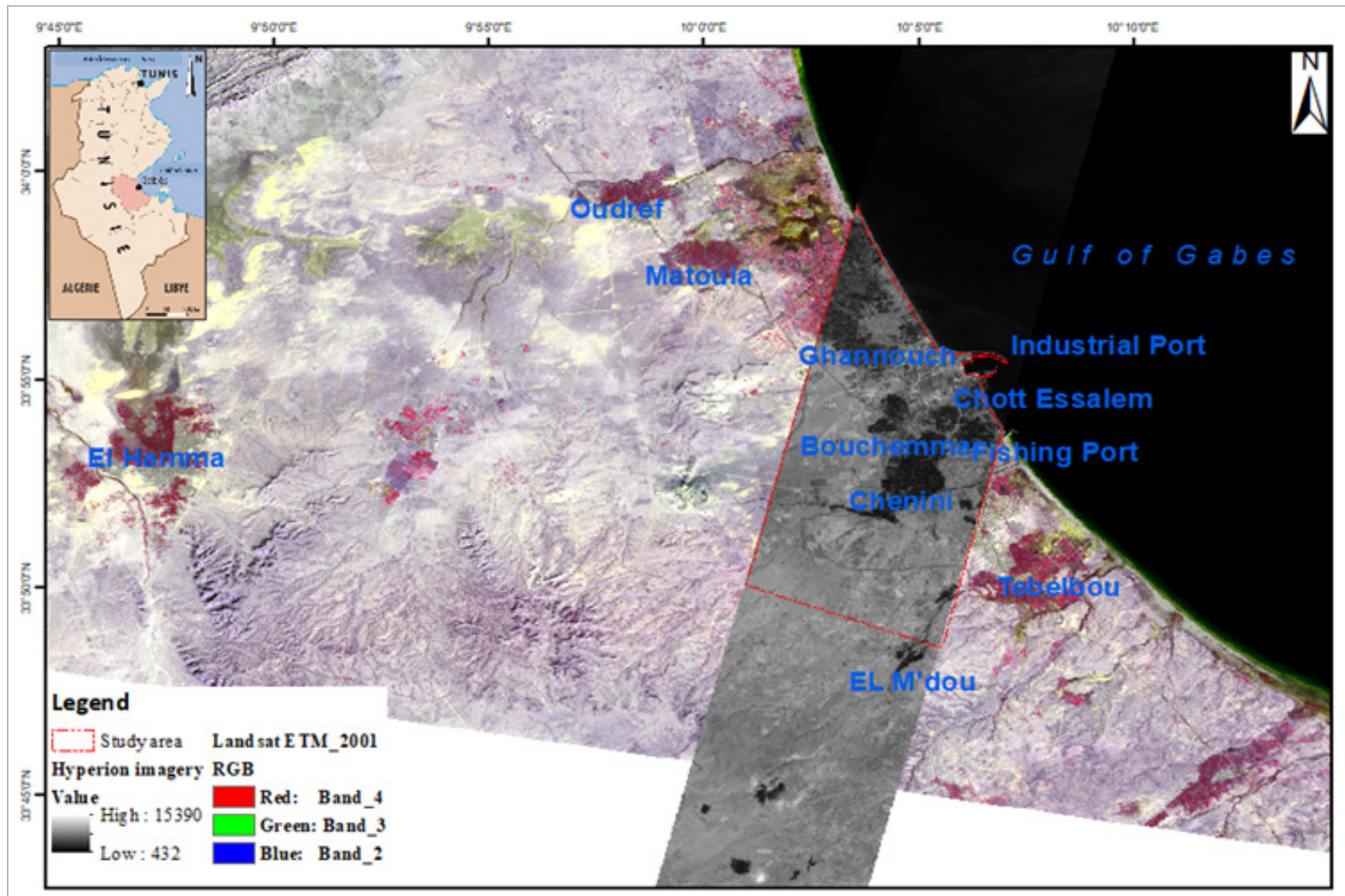

Figure 1. Location map of Gabes Oasis observed from Hyperion data 25 April 2010 (position on a background of a Landsat image).

Southern Tunisia, which makes them subject to commercial traffic.

Agriculture in the Gabes region has also been changing under the decreasing availability of water resources, which are phreatic and deep. Presently, the main water resource comes from the exploitation of fossil groundwater. However, both qualitative and quantitative degradation of the groundwater resource is a result of the overexploitation of the Jeffara aquifer for socio-economic and agricultural purposes. The aquifer system of Gabes has been guided by the regional geological structure: the Jeffara water table is mainly recharged by water flowing through the NNW/SSE El Hamma Fault extending from the Gafsa tectonic fault to the south. ${ }^{14}$ Increased exploitation of the water table to the east of this fault has caused lowering of the water table and drying in the northern part of Jeffara. ${ }^{15}$

The effect of industrialisation on Gabes' oases in the 1970s was driven by the Tunisian State: the Gulf of Gabes was chosen to accommodate phosphate processing industries backed by a port for exporting. This industrial centre has created thousands of jobs in the cities of Gabes and Ghannouch, attracting not only a population formerly working in the oases but also nomads and people from remote rural areas. Thus, the urban population of Gabes Governorate increased from $55 \%$ to $68 \%$ from 1975 to $2000 .{ }^{12}$ Whilst oases may have lost their workforce, they have also restructured due to intensification of agriculture. Old and peri-urban oases have been partially abandoned in favour of the new irrigated areas. The port remains an export route for agricultural products, such as pomegranate and olives, consumed in Tunisia and Europe, the production of which was previously restricted to the local market. The territory has become an urban area located in an almost continuous agricultural space. Urban pressure was very strong in irrigated areas, as the ground had a higher value as development land than as farmland. ${ }^{12}$ However, this bifurcation in economic policies toward the development of industry 
has led to a shortage of traditional expertise and of the farm workforce. ${ }^{16}$

\section{Data and methods}

\section{Data acquisition}

Two complementary datasets (i.e., remote sensing and field observations) were analysed in this paper to map the state of vegetation cover of the Gabes oases.

\section{Hyperion imaging}

The Hyperion sensor is on the experimental satellite EO1 (Earth Observer One) and was the first spaceborne hyperspectral device. Launched by NASA on 21 November 2000, the orbit supports a 16-day repeat cycle, a coordinated tandem orbit within a minute of Landsat-7. ${ }^{17}$ This hyperspectral sensor has an innovative design and the capacity to record a continuous electromagnetic spectrum from $400 \mathrm{~nm}$ to $2500 \mathrm{~nm}$. It studies radiation from the Earth's surface in 242 spectral bands at 10-nm intervals with 30-m pixel size and a swath width of $8 \mathrm{~km}$. Due to the narrowness of its swath, this sensor does not operate in systematic acquisition mode but by programming. ${ }^{17}$ The Hyperion data were acquired on 25 April 2010 from the archives of the USGS (http:// earthexplorer.usgs.gov) and it covered the main oases of Gabes, namely Ghannouch, Bouchemma, Chott Essalem and Chenini (Figure 1).

\section{Field observations}

Due to the complexity of the oasis environment, including the presence of overlapping tree layers and small plots of land, the results from remote sensing were verified through field observation. Three field missions were carried out in the Spring of 2009, 2010 and 2011, before and after harvest, to collect several types of data: topographic surveys and GPS tracking, observations and field photographs, qualitative surveys, and questionnaires. However, it was not possible to retrieve the instantaneous state of the crops in any of the missions as their state can vary rapidly due to irrigation, farm transmission methods and agricultural diversity in each of the oases studied. ${ }^{18}$ As a result, GPS surveys and photographs were examined to produce a spatial inventory of Gabes oases. Field observations have revealed the perennial characteristics of the territory at a multi-year scale: state of the irrigation system, density of the woody cover, organisation of the plot, abandonment of the farm and signs of environmental stress. These surveys were supplemented by interviews with the farmers, key players in landscape change and the recent evolution of the territory, in order to gain insight into their perceptions of the oasis environment evolution. By a semi-directed survey technique, about 30 people from different socio-professional categories were interviewed. They were mainly farmers, staff of associations and administrative employees. The main themes of the questionnaire were water, irrigation system, practices and production strategy. These data allow a global and precise view of the evolution of oases agro-ecosystems and their environmental challenges, to validate output EO1 data.

\section{Methods}

Figure 2 illustrates data processing from spatial and local approaches.

\section{Processing Hyperion imagery}

Atmospheric correction

Because of the spectral coverage of the Hyperion bands, it is imperative to eliminate the disturbances caused by atmospheric effects (i.e., water vapour, aerosols). The corrections were conducted using the 6s software, ${ }^{19}$ which allows the modelling of radiative transfer in the

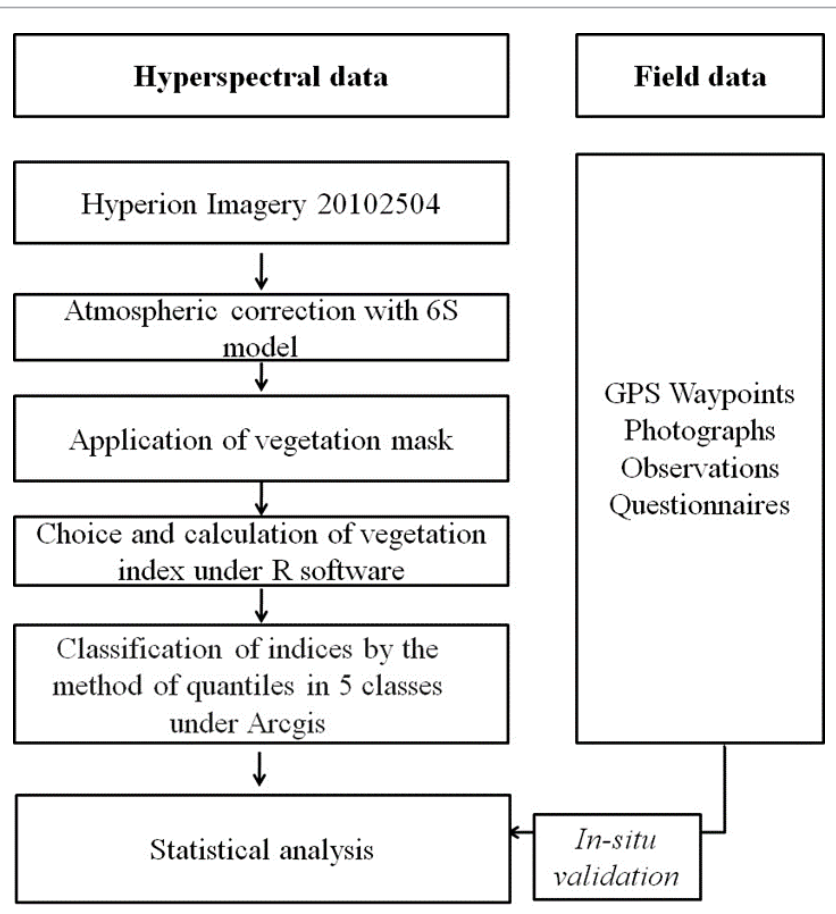

Figure 2. Methodological development. 
visible spectrum with a resolution of $5 \mathrm{~nm}$. In order to speed up the calculations, the second-order spherical albedo term was not considered. The atmospheric correction is reduced to a linear transformation whose coefficients are constant on a spatial extension scene limited to a few square kilometres. The corrections depend on three atmospheric parameters: the ozone content, the water vapour and the optical thickness at $550 \mathrm{~nm}$. Only the first parameter was extracted from the climatology provided by $6 \mathrm{~s}$. The water vapour content was provided by the re-analysed NOAA/NCEP-DOE (https://www.esrl. noaa.gov/psd). The optical thickness was deduced from Hyperion measurements of the sea off Gabes and by reversal of the 6s model. The 6SV 2.1 version was downloaded from http://6s.Itdri.org.

\section{Application of the vegetation mask}

The densely vegetated zones represented only a small part of the Hyperion scene. In order to improve the statistical validity of the results, other types of the land surface (rangeland, sea, urban area) were eliminated by applying a vegetation mask. The method of Reference 20 was used, allowing each pixel to determine the wavelength with minimum reflectance between $426 \mathrm{~nm}$ and $760 \mathrm{~nm}$ and then classifying this pixel as "green" if this wavelength is $680 \mathrm{~nm}$. The physical justification for this method is that chlorophyll is characterised by a red absorption peak at $680 \mathrm{~nm}$ (band 33 of Hyperion). This phenomenon appears in the spectral signature of the land use in the study area according to EO1 bands (Figure 3).

\section{Design and calculation of the hyperspectral indices}

Because of variations in pigment content, the radiometric response of vegetation indices is a sensitive indicator of

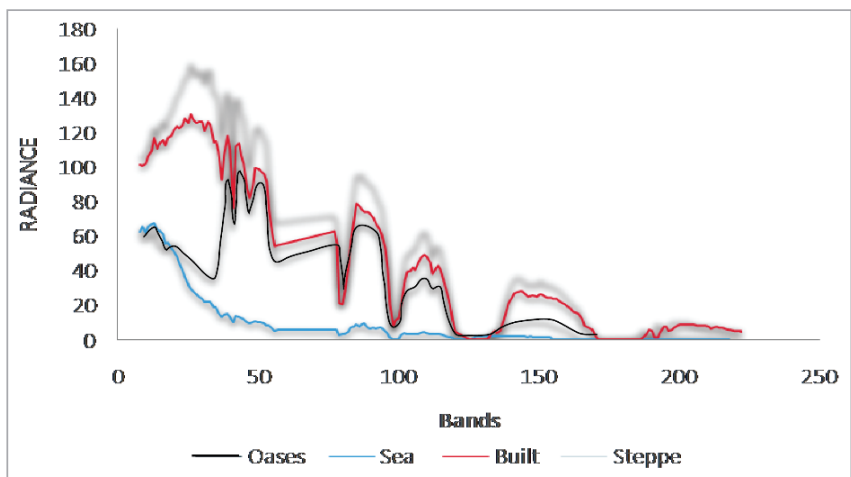

Figure 3. Spectrum of different land cover classes in the study area.

photosynthetic activity, nutritional status of the plant and stress in cultivation. ${ }^{21}$ In a study on the potential of hyperspectral remote sensing for precision agriculture, the authors identified various indices derived from satellite sensors. ${ }^{22}$ Four of them were selected in this study reflecting the physiological state of the leaves due to variations in pigment content. ${ }^{23}$

Table 1 shows the list of indices analysed in the study area:

1) The Normalised Difference Vegetation Index (NDVI) developed by Gitelson et al. ${ }^{24}$ is commonly used. It highlights the difference between the visible red and near infrared bands. The NDVI is defined by the following equation using the hyperspectral bands:

$$
\mathrm{NDVI}=\frac{R 800-R 680}{R 800+R 680}
$$

2) The Anthocyanin Reflectance Index (ARI) proposed by Gitelson et al. ${ }^{24}$ is a sensitive measure of the anthocyanin pigments content responsible for the red

Table 1. Calculated indices.

\begin{tabular}{|l|l|c|c|}
\hline Index & Abbreviation & Formulae & References \\
\hline Normalised Difference Vegetation Index & NDVI & $\frac{R 800-R 680}{R 800+R 680}$ & 23 \\
\hline Anthocyanin Reflectance Index & ARI & R800 $\left[\left(\frac{1}{R 550}\right)-\left(\frac{1}{R 700}\right)\right]$ & 24 \\
\hline Photochemical Reflectance Index & PRI & $\frac{R 531-R 570}{R 531+R 570}$ & 30 \\
\hline Disease Water Stress Index & DWSI & $\frac{R 800+R 550}{R 1660+R 680}$ & 32 \\
\hline
\end{tabular}


pigmentation in the leaves. With strong antioxidant activity, anthocyanins occur due to different environmental stresses ${ }^{25}$ such as excessive light, ${ }^{26} \mathrm{UV}$ rays $^{27}$ and cooling. ${ }^{28}$ Therefore, the estimation of anthocyanin content and the interaction between anthocyanins and chlorophylls contained in the leaves may be a useful tool for diagnosing the stress of individual trees and ecosystems. ${ }^{29}$ The ARI is defined by the following equation:

$$
\mathrm{ARI}=\mathrm{R} 800 \times\left[\left(\frac{1}{R 550}\right)-\left(\frac{1}{R 700}\right)\right]
$$

3) The Photochemical Reflectance Index (PRI) proposed by Gamon et al. ${ }^{30}$ exploits the reflectance properties in the narrow bands around $531 \mathrm{~nm}$ in relation to xanthophyll pigments. This pigment has the property of absorbing in the wavelength $505 \mathrm{~nm}$ and reflecting at $531 \mathrm{~nm}$ according to its level of de-epoxidation. From a physiological point of view, the xanthophyll cycle is activated when light absorption increases. Through the PRI, monitoring the xanthophyll cycle indirectly provides a measure of the short-term change in the plant's efficiency in using light or even the photosynthetic capacity of the leaves. ${ }^{31}$ The PRI is defined by the following equation:

$$
P R I=\frac{R 531-R 570}{R 531+R 570}
$$

4) The Disease Water Stress Index (DWSI) ${ }^{32}$ was designed to evaluate the yields of sugar cane farms. It combines a plant health indicator with an indicator of water stress. It is defined by the following equation:

$$
D W S I=\frac{R 800+R 550}{R 1660+R 680}
$$

\section{Validation of EO1 data}

The results obtained with the proposed processing of the Hyperion image was evaluated both quantitatively and qualitatively. The quantitative approach was based on statistical analyses. A discretisation of the five-class indexes according to the Quantile method was carried out using ArcGIS software. In addition, regression analysis and correlation coefficient determination were performed to deduce linear relationships between the different indices. Two-dimensional histograms were generated for the NDVIs. While the qualitative approach is based on the comparison of the results with the field observation, the choice of control points was directed according to the different classes of indices. We attempted, through the analysis of the landscape, over 10 points throughout the area, to define a typology of the state of the oasis plant cover based on the field surveys.

The map of the vegetation cover in Gabes oases was based on an atmospherically corrected, vegetation masked hyperspectral image and the four most popular vegetation indices: NDVI, ARI, PRI and DWSI. In order to evaluate the usefulness of the information obtained with these indices, statistical analyses were considered. However, to compare the index, we opted for the discretisation of values within a range of five classes by using the Quantile method using the ArcGIS software. An analysis of the regression relationships of the different generated classes was established. Additionally, field observations made it possible to complete the processing and to achieve the mapping results. An in situ validation method was directed according to the classes of the indices. We chose control points corresponding to the combinations of contrasting indices.

\section{Results}

The spatial variability of the hyperspectral indices in each oasis territory is shown in Figure 4 and their classification demonstrated that the spatial response of the indices, DWSI and PRI, is fairly close to the NDVI. Nevertheless, this mapping showed different values for ARI. Taking into account the definition of this index and its properties at the leaf scale, it can be hypothesised that an increase in anthocyanin, relative to chlorophyll, provided a defence indicator in the presence of stress affecting plants.

A validation of this suggested hypothesis with the field reality was carried out from 10 samples spread over the whole area (Figures 1, 5 and 6). Field observations revealed that the structure of the oasis territory has an internal heterogeneity linked to several factors, mainly of anthropogenic origins: expansion of industry, lack of water and fragmentation of agricultural land. However, specialisation of each territory was observed according to its geographical, water and economic characteristics. Figure 5 provides statistical analyses of selected vegetation indices for validation with field observations.

The NDVI values allowed better discrimination of the levels of chlorophylls in each oasis territory compared 


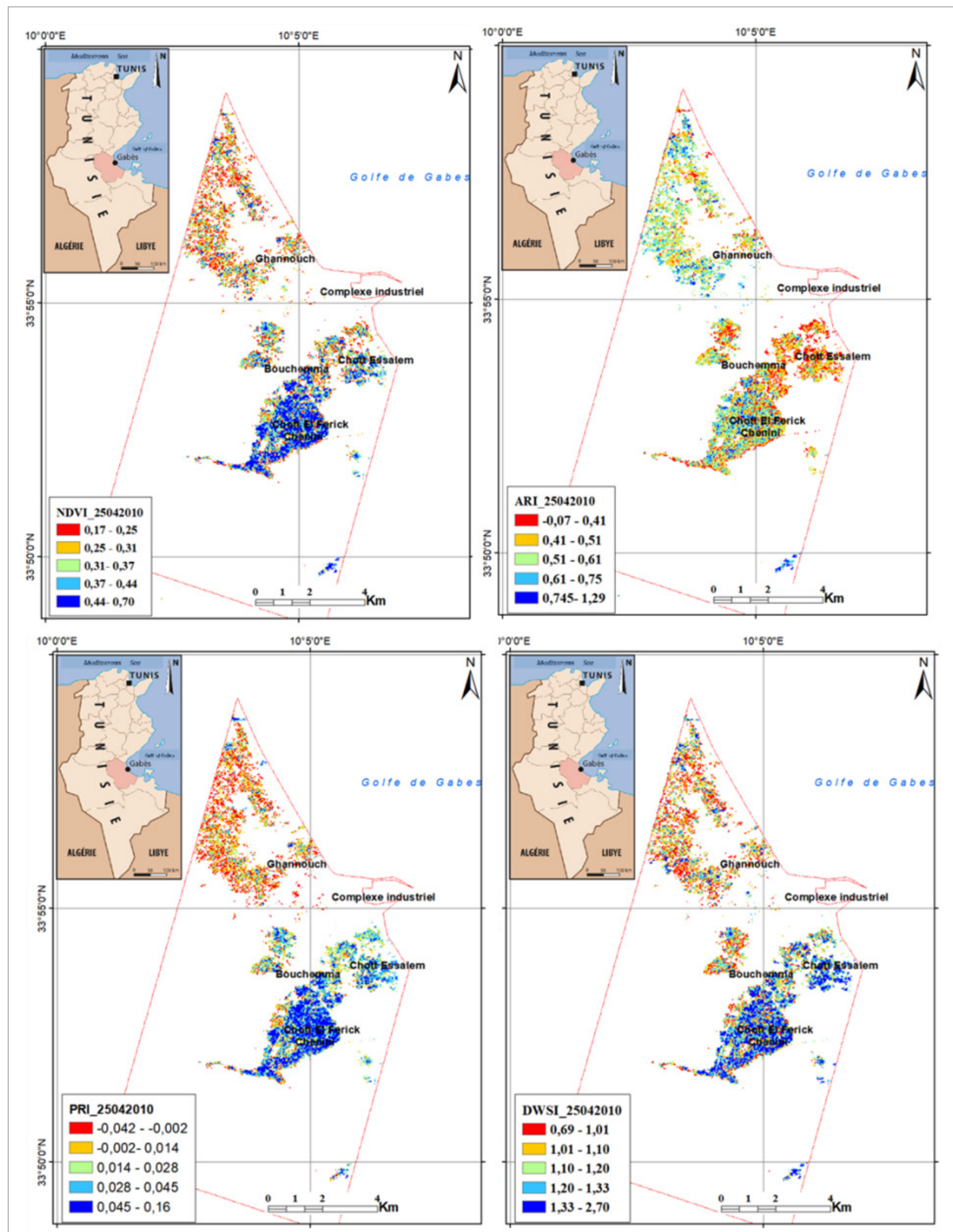

Figure 4. Index mapping by the quantile method. 


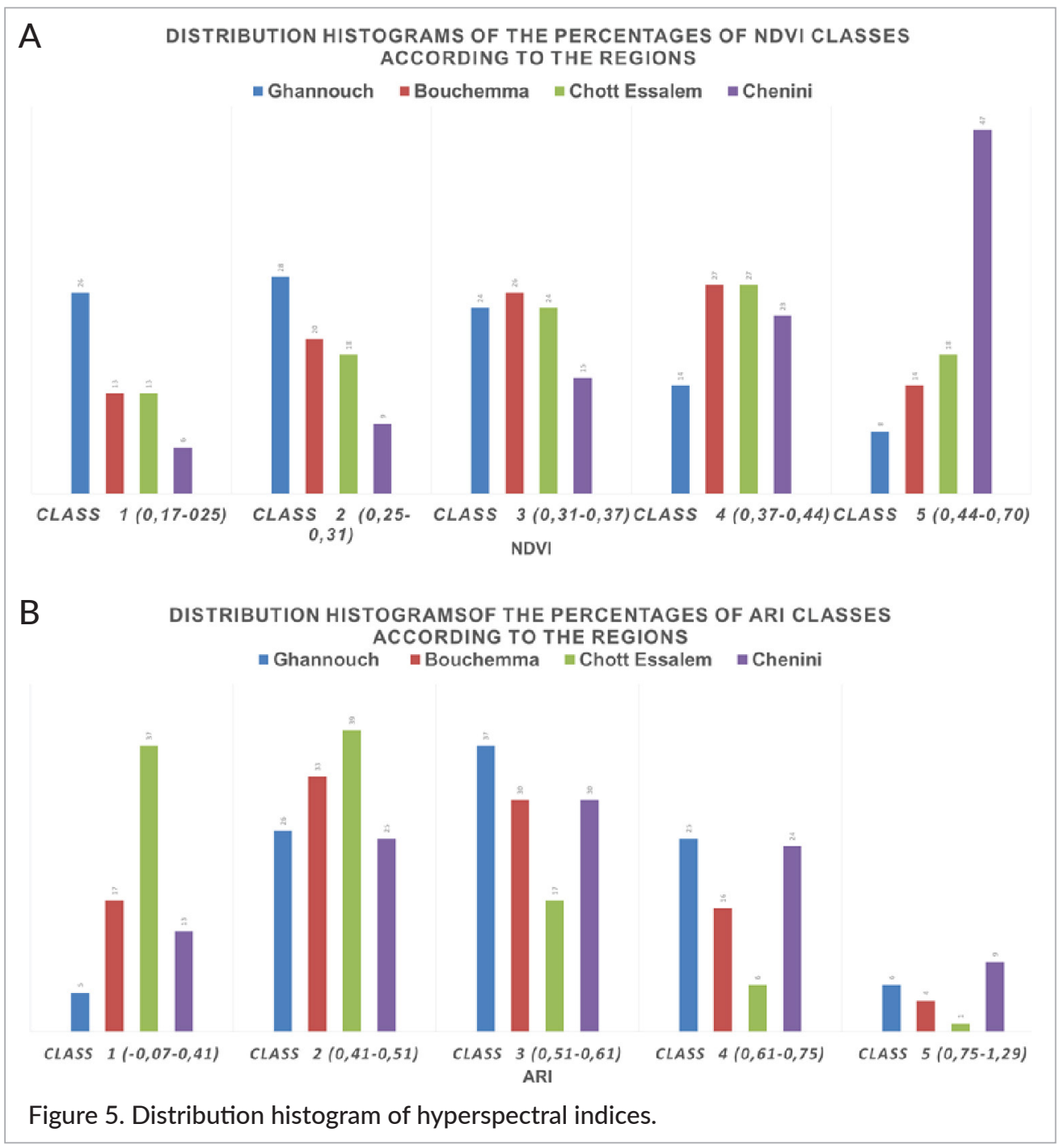

to the surrounding steppe. The combination of $800 \mathrm{~nm}$ and $680 \mathrm{~nm}$ provided reliable estimates of chlorophyll levels making it possible to differentiate oasis territories according to the density of the crops and the vegetation layers. The analysis of the distribution histograms of the NDVI class percentages according to the regions (Figure 5A) showed that the class with high NDVI value (Class 5 with $47 \%$ ) is concentrated in Chenini where several types of land use dominated. There are dense palm groves (Figure 6, photo i) and vegetated surfaces with three strata: palm trees marking the boundaries of plots, fruits trees and vegetable or forage crops (Figure 6, photo j), some of which are characterised by specialisation of production systems (pomegranates, olives, market gardening, fodder, livestock). ${ }^{33}$ According to the farmers, the specialised sectors are linked to the fragmentation of land in the face of the land inheritance of their parents and grandparents. The middle classes (class 3 and 4) of NDVI values represented $26 \%$ and $27 \%$, respectively, in Bouchemma (Figure 6, photo b) and $24 \%$ and $27 \%$, respectively, in Chott Essalem (Figure 6, photo a) where the dominant vegetated surfaces have two layers. The Iow NDVI values represented by Class 1 and Class 2 with $26 \%$ and $27 \%$, respectively, at Gannouch dominated by herbaceous culture (Figure 6, photos e and f), 13\% and $20 \%$, respectively, at Bouchemma (Figure 6, photo h) and $13 \%$ and $18 \%$, respectively, at Chott Essalem, marking the steppe (Figure 6, photo c).

ARI is an indicator of stress affecting the plants. The analysis of the class histogram of this index (Figure $5 \mathrm{~B})$ shows that the low values at Chott Essalem (Class $1=37 \%$; Class 2 = 39\%) and Bouchemma (Class 1=17\%; Class $2=33 \%$ ) was due to two-layer spaces, which are dominated by both water and air pollution because of 


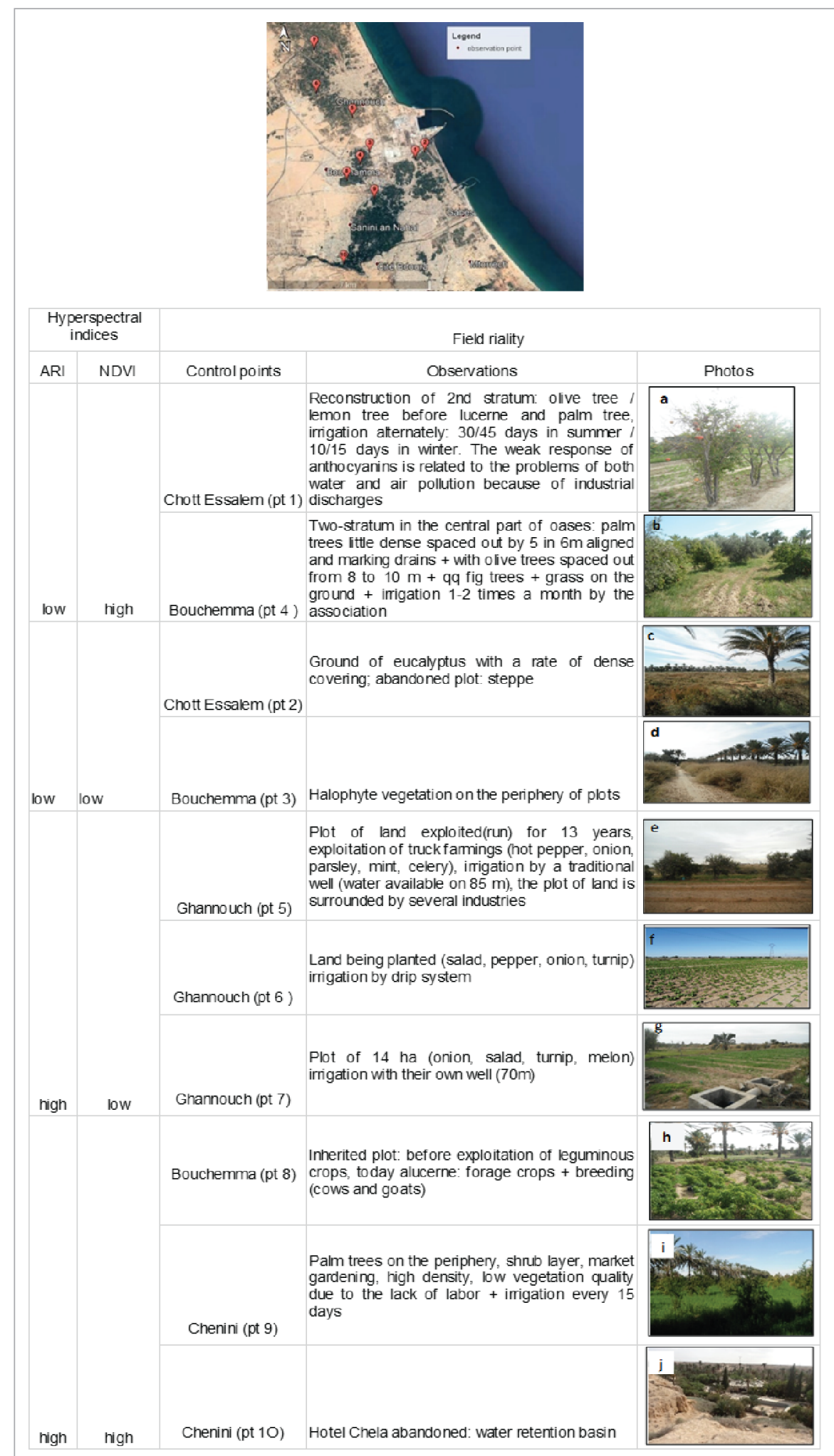

Figure 6. Summary of the field observations. 
industrial discharges very close by. The mean ARI values were observed on vegetated surfaces with herbaceous cultures at Ghannouch (Class 3=37\%; Class $4=25 \%$ ), in Chenini (Class 3 $=30 \%$; Class $4=24 \%$ ) and at Bouchemma (Class $3=30 \%$; Class $4=16 \%$ ). In these territories, the problems encountered are related to the distribution of water. The high values of ARI appeared with low percentages, $9 \%$ at Chenini, $6 \%$ at Ghannouch, $4 \%$ at Bouchemma and $1 \%$ at Chott Essalem. These areas are occupied by sick palm trees delimiting the plots.

The field observations and the analysis of the hyperspectral vegetation indices NDVI and ARI revealed that the extension of Gabes' oases on the margins of the new irrigated areas was accompanied, on a fine scale, by qualitative changes in the state of the vegetation cover. This degradation influenced different agricultural areas on a regional scale, but the magnitude of this phenomenon varied spatially. The proposed typology of oases is based on the factors of degradation or the types of stress influencing the oasis vegetation:

where the two indices are weak, it corresponds to abandoned plots or plots with halophyte vegetation;

where the two indices are strong, it represents densely vegetated plots;

where ARI is weak and NDVI is strong, it represents two-layer plots, where the problems of water and air pollution are dominant due to industrial discharges; and

where ARI is strong and NDVI is weak, this coincides with vegetated zones with herbaceous stratum and water stress dominance.

\section{Discussion and conclusions}

The use of hyperspectral imagery highlighted the potential of the Hyperion sensor in the mapping and analysis of oases' vegetation cover with heterogeneous structures and subjected to anthropogenic constraints. It also helped in the characterisation of the qualitative state of the oases, i.e., their vulnerability to socio-environmental changes. Although only one scene covering a large part of the oasis sites was available (25 April 2010), the derived indices provided additional information to the vegetation index. This scene exhibited great spatial variability within the oasis territory, the variability appeared clearly through the Hyperion data with a relatively fine spectral scale. To analyse this variability, four commonly used indices were tested. Among them, the NDVI and ARI were weakly correlated, making it possible to define an adequate typology of the oasis' territory. Their mapping was validated by field observations. This study highlighted the value of NDVI and ARI in the characterisation of the state of vegetation cover. NDVI showed gradual variation in vegetation cover distinguished by vegetative strata and crop density. The spatial variability of ARI makes it possible to differentiate the geographical zones with healthy vegetation from areas of vegetation subjected to socio-environmental stresses.

The result of the spatial distribution of the calculated indices and its validation to field observations indicates that the changes in oasis agriculture are linked to several factors. The coastal oases are threatened by intensive use of water resources by industry, tourism and urban areas. The decrease in water availability results from over-exploitation and poor management of irrigation resources. In addition, there is a shortage of agricultural manpower and know-how since the installation of the industrial complex in Gabes, which attracted many of the important agricultural workforce. Air pollution may have had a negative effect on the health of the vegetation of some oases close to the industrial zone (Chott Essalem, Bouchemma, Ghannouch). The problem of land fragmentation due to inheritance within families is also encountered, explaining the abandonment of certain plots where there is no possibility of expansion. These different factors have changed the production strategies and behaviours of the farmers. Farmers have developed new types of cultivation (plant breeding, tree-growing, horticulture etc.), whilst keeping some palm trees on the boundaries of their plots for their benefits in climate control and landscaping.

Finally, the Hyperion sensor had a number of limitations, such as missing spectral bands, poor signal-tonoise ratio and the fact that the image only covered a swath of $8 \mathrm{~km}$. Despite these issues, this sensor provides a fine resolution for the analysis of the land use. It has strong potential for the detection of vegetation properties, thanks to its continuous spectrum over a wide spectral range $(400-2500 \mathrm{~nm})$. This fine spectral resolution allowed better discrimination of the oasis territory. However, the results have often been obtained in an experimental framework and they need to be validated against a wider range of oases. 


\section{Acknowledgements}

This work has received financial support from the LabEx DynamiTe (ANR-11-LABX-0046), as part of the "Investissements d'Avenir". Our sincere thanks to Jouda.

\section{References}

1. I. Carpentier and A. Gana, "Les oasis de Tozeur et Chenini Gabès : diversité et durabilité des formes de valorisation à l'ère de la mondialisation et des crises du développement", in Actes du Colloque Oasis dans la Mondialisation: Ruptures et Continuités, Ed by A. Marshall, E. Lavie, J.L. Chaleard, M. Fort and J. Lombard, Dec 2013, Paris, France. pp. 105-112 (2014).

2. V. Battesti, Jardins au Désert, Evolutions des Pratiques et Savoirs Oasiens, Jerid Tunisien. Editions IRD, Paris (2005).

3. S. Abdedayem and B. Veyrac-ben ahmed, "Le paradoxe des oasis du sud tunisien: rénovation ou mort d'un concept", in Actes du Colloque Oasis dans la Mondialisation: Ruptures et Continuités, Ed by A. Marshall, E. Lavie, J.L. Chaleard, M. Fort and J. Lombard, Dec 2013, Paris, France. pp. 21-28 (2014).

4. A. Hatira, L. Baccar, M. Grira and T. Gallali, "Analyse de sensibilité du système oasien et mesures de sauvegarde de l'oasis de Métouia (Tunisie)", J. Water Sci. 20(1), 59-69 (2007). https://doi. org/10.7202/014907ar

5. J. Lombard, E. Mesclier and S. Velut, La Mondialisation Côté Sud: Acteurs et Territoires. Editions IRD, Paris (2006).

6. G. Beltrando, Les Climats. Processus, Variabilité et Risques. Armand Colin, coll. U, Paris (2004).

7. S. Abdedayem, La Gestion de L'eau et son Impact sur la Dynamique des Systèmes de Production dans les Oasis Littorales du Sud Tunisien, Cas de L'oasis de Gabes, Mémoire pour L'obtention du Diplôme D’ingénieur des Techniques Agricoles des Régions Chaudes. CNEARC, Montpellier (1997).

8. S. Maimouni, A. Bannari, A. El-harti and A. El-ghmari, "Potentiels et limites des indices spectraux pour caractériser la dégradation des sols en milieu semiaride", Can. J. Remote Sens. 37(3), 285-301 (2011). https://doi.org/10.5589/m11-038
9. B.W. Pengra, C.A. Johnston and T.R. Loveland, "Mapping an invasive plant, Phragmites australis, in coastal wetlands using the EO-1 Hyperion hyperspectral sensor", Remote Sens. Environ. 108, 74-81 (2007). https://doi.org/10.1016/j.rse.2006.11.002

10. R. Pu, Q. Yu, P. Gong and G.S. Biging, "EO-1 Hyperion, ALI and Landsat 7 ETM+ data comparison for estimating forest crown closure and leaf area index", Int. J. Remote Sens. 26, 457-474 (2005). https://doi.org/10.1080/01431160512331299324

11. P.S. Thenkbail, E.A. Enclona, M.S. Ashton, C. Legg and M.J. De dieu, "Hyperion, IKONOS, ALI and $\mathrm{ETM}+$ sensors in the study of African rainforests", Remote Sens Environ. 90, 23-43 (2004). https://doi. org/10.1016/j.rse.2003.11.018

12. S. Abdedayem, Mutations Socio-Spatiales et Modes de Gouvernance de L'eau dans les Oasis Périurbaines du Gouvernorat de Gabès (Sud-est Tunisien). Université Paris 10 (2009).

13. Ch. Riou, "Une formule empirique simple pour estimer l'évapotranspiration potentielle moyenne en Tunisie", Coh. ORSTOM, sér. Hydrol., Vol. XVII, No. 2, pp. 129-137 (1980).

14. F. Zargouni, M.C. Rabia and C. Abbes, "Rôle des couloirs de cisaillement de GAFSA et de Negrine Tozeur dans la structuration du faisceau des plis des Chotts, elements de l'accident sud-atlasique", CR Acad. Sci. Paris 301(II), 831-834 (1984).

15. M. Ben alaya, T. Zemni, A. Mamou and F. Zargouni, "Acquisition de salinité et qualité des eaux d'une nappe profonde, Tunisie: approche statistique et géochimique", Hydrolog. Sci. J. 59(2), 395-419 (2014). https://doi.org/10.1080/02626667.2013.870663

16. J. Ben arfa, R. Katlane, F. Zargouni, J.C. Bergès, E. Lavie and G. Arnaud-fassetta, Detection Vegetation Changes in Oases of Gabes Using EO1/Hypérion Data. First Euro-Mediterranean Conference for Environmental Integration (EMCEI) (2017).

17. USGS, EO-1 User's Guide (2003). http:// www.pancroma.com/downloads/ EO1userguidev2pt320030715UC.pdf

18. M. Mboup, Changements Socio-Environnementaux et Dynamique de la Végétation Aquatique Envahissante dans le Delta du Fleuve Sénégal. Thèse de doctorat, Environnement littoral (2014).

19. E.F. Vermote, D. Tanré, J.L. Deuzé, M. Herman and J.-J. Morcrette, "Second simulation of the satellite signal in the solar spectrum, 6S: an overview", IEEE 
Trans. Geosci. Remote Sens. 35(3), 675-686 (1997). https://doi.org/10.1109/36.581987

20. C. Wu, Z. Niu, Q. Tang and W. Huang, "Estimating chlorophyll content from hyperspectral vegetation indices: modeling and validation", Agric. Forest Meteorol. 148, 1230-1241 (2008). https://doi. org/10.1016/j.agrformet.2008.03.005

21. M.L. Whiting, S.L. Ustin, P. Zarco-Tejada, A. PalaciosOrueta and V.C. Vanderbilt, "Hyperspectral mapping of crop and soils for precision agriculture", Proc. SPIE 6298, 62980B (2006). https://doi. org/10.1117/12.681289

22. D.A. Sims and J.A. Gamon, "Relationships between leaf pigment content and spectral reflectance across a wide range of species, leaf structures and developmental stages", Remote Sens. Environ. 81, 337-354 (2002). https://doi.org/10.1016/S00344257(02)00010-X

23. J.W. Rouse and H. Haasr, "Monitoring vegetation systems in the great plain with ERTS", in Third ERTS Symposium. NASA, Washington, DC, Vol. 1, pp. 309-317 (1973).

24. A.A. Gitelson, M.N. Merzlyak and O.B. Chivkunova, "Optical properties and nondestructive estimation of anthocyanin content in plant leaves", Photochem. Photobiol. 74, 38-45 (2001). https://doi. org/10.1562/0031-8655(2001)074<0038:OPANEO $>2.0 . \mathrm{CO} ; 2$

25. S. Barris and A. Belkebir, "Effet d'une contrainte hydrique sur les chlorophylles, l'accumulation du $\mathrm{H}_{2} \mathrm{O}_{2}$ et les anthocyanes des plantules de colza (Brassicanapus L.), Rev. Régions Arides 35, 920-925 (2014).

26. D.C. Close and C.L. Beadle, "The ecophysiology of foliar anthocyanin", Bot. Rev. 69, 149161 (2003). https://doi.org/10.1663/00068101(2003)069[0149:TEOFA]2.0.CO;2
27. M. Mendez, D.G. Jones and Y. Manetas, "Enhanced UV-B radiation under field conditions increases anthocyanin and reduces the risk of photoinhibition but does not affect growth in the carnivorous plant Pinguicula vulgaris", New Phytol. 144, 275-282 (1999). https://doi.org/10.1046/j.1469-8137.1999.00511.x

28. L. Wen, T. Chen, M. Zhang, Y. Wang, Y. Zhang, Z. Duan, L. An, Q. Jian and R. Peng, "High contents of anthocyanins in young leaves are correlated with low pools of xanthophyll cycle components and low risk of photoinhibition", Acta Physiol. Plant. 32, 801-808 (2010). https://doi.org/10.1007/s11738010-0465-2

29. M.S. Mielke, B. Schaffer and A.C. Schilling, "Evaluation of reflectance spectroscopy indices for estimation of chlorophyll content in leaves of a tropical tree species", Photosynthetica 50(3), 343-352 (2012). https://doi.org/10.1007/s11099-012-0038-2

30. J.A. Gamon, J. Penuelas and C.B. Field, "A narrow-waveband spectral index that tracks diurnal changes in photosynthetic efficiency", Remote Sens. Environ. 41, 35-44 (1992). https://doi. org/10.1016/0034-4257(92)90059-S

31. L. Serrano and J. Penuelas, "Assessing forest structure and function from spectral transmittance measurements: A case study in a Mediterranean holm oak forest", Tree Physiol. 25, 67-74 (2005). https://doi. org/10.1093/treephys/25.1.67

32. A. Apan, A. Held, S. Phinn and J. Markely, "Detecting sugarcane orange rust disease using EO-1 Hyperion Hyperspectral imagery", Int. J. Remote Sens. 25, 489-498 (2004). https://doi.org/10.1080/01431160 310001618031

33. M. Haddad, "Les systèmes de production et les techniques culturales en milieu oasien (Oasis de Gabès, Tunisie)", New Mediterranean 2, 38-43 (2007). 